\title{
"PERMANENT" GIRLFRIEND: ENABLING DISPLACEMENTS IN THE WORLD OF SUZIE WONG
}

Taylor Harrison

"Everybody say, 'Where is Suzie, for goodness sake?’”
Suzie Wong (Nancy Kwan) in The World of Suzie Wong

In the realms of dualities where blinding brilliance is opposed to mysterious luminosity...she finds no place she can simply dwell in or transgress. Crisscrossing more than one occupied territory at a time, she remains perforce inappropriate/d-both inside and outside her own social positioning....A trajectory across variable praxes of difference, her (un)location is necessarily the shifting and contextual interval between arrested boundaries.

Trinh T. Minh-ha, When the Moon Waxes Red

Robert Lomax (William Holden), an architect, gives up his job in the United States to move to Hong Kong and try his luck for a year as an artist. Inadvertently, he ends up living in the Nam Kok Hotel in the Wanchai district, where prostitutes ply their trade with sailors on leave. Robert falls in love with Suzie Wong (Nancy Kwan), a prostitute who works at the Nam Kok bar and models for Robert's paintings. After much plot wrangling, Robert decides to marry her.

This is one version of the story told in the film The World of Suzie Wong (1960). But try another: a white man feels uneasy in the place awarded him by the dominant culture. He unsettles his positioning by re-placing himself in a milieu of difference, where his set standards do not apply. Confronted by the fact of difference, yet unable to extricate himself and obtain sufficient, appropriate distance from his (newly) adopted place, he experiences crises in his subjectivity. Finally, he regains a certain balance by readjusting his world-view (worldnarrative), but the solution is precarious and seems to admit that no positioning can "actually" be secured. 
One more account: a white man, aware that his position of cultural dominance is bankrupt but unwilling to jeopardize his institutional/cultural power, widens his discursive field to include "other," unsanctioned texts and cultural artifacts. He colonizes those texts of the "other," relying on an unaltered theoretical apparatus to enable his readings. He calls himself and his task "progressive," and under this guise continues to oppress.

What is The World of Suzie Wong "about"? The very existence of more than one reading indicates that it is "about" a lot of things, that the critic/theorist is not obligated to read one ultimate "meaning" in and from a filmic text. I want, in this paper, to mobilize that text in many different ways in order to demonstrate (illustrate?) the working through of a position.

One way to begin to accomplish this project is through a tactical use of various texts. The idea is not to take one text and "apply" it to another, for "application" seems to imply the laying of one text over another. Instead, I will locate texts relationally near each other in various configurations, to use them in order to speak. The value of this project lies not in the hermeneutic result, that is, the interpretation, but on the process, the "how" of arriving at an interpretation. Consequently, I will read moments from my chosen texts that show how I came to think about them the way I do-those which foreground the "how," the presence of process, a struggle.

Cultural theorist Meaghan Morris wrestles in her work with the theoretical and textual advantages of such an approach, as well as with its consequent difficulties. In "Tooth and Claw: Tales of Survival and Crocodile Dundee," she tells a story of power, or rather, a crisis of power-a moment when radical criticism and theory begin to doubt that they can affect textual production or consumption in ways that can be read as positive. Radicalism thus finds itself in the terrifyingly ineffectual position of perpetuating the dominant rather than subverting it, and Morris finds herself asking why anyone should claim to be radical under such circumstances. Indeed, what purpose would a professed radical politics serve at all?

At the heart of the impasse, Morris suggests, lies the mistake of conceiving of critical activity, and texts themselves, as either good or bad, radical or not, effective or ineffective. Her consequent struggle-occasionally successful, occasionally not-is one that I share: how to change one's deeply ingrained ways of thinking so that such polar opposites do not hold sway, do not convince. Learning to read for relationships which point, to use Morris's words, to "difference in terms of more than two" ("Pirate's Fiancée" 36) may be the only way to begin to come to a solution.

Lest one feel left in the lurch here-that is, with an awareness of a pressing problem, but with no hope of finding even a contingent solutionMorris writes of the difference between "strategy" and "tactics" as a way of evading a simple valorizing of the clearly-defined oppressed and their activities against their equally clearly-defined oppressors. Morris argues: 
Strategy presupposes a place of its own, one circumscribed as "proper," and so predicates an exterior, an "outside," an excluded Other....Tactics, however, are localized ways of using what is made available-materials, opportunities, time and space for action — by the strategy of the other, and in "his" place. They depend on arts of timing, a seizing of propitious moments, rather than on arts of colonizing space. ("Banality" 29)

Rather than assigning values to cultural practices and texts adhering to poles of positive or negative, radical or conservative, which would locate them strategically in clearly defined political spaces, Morris instead devotes her energies to the development of contingent, time-dependent tactics to be deployed in relation to those practices and texts. She embraces "a politics...of the provisional and the definitely uncertain" ("Pirate's Fiancée" 21). "Provisional" denotes tactical contingency; "definitely uncertain": for how long will this tactic remain useful? Not for all time, but perhaps, and carefully, for the moment.

Following Morris's argument, a useful reading of a text requires an acknowledgement of itself as a process of precisely the "provisionalizing" and "uncertainizing" of its meanings. Such readings may be accomplished through a process of self-reflexive repetition. As Trinh T. Minh-ha writes:

When repetition reflects on itself as repetition, it constitutes this doubling back movement through which language (verbal, visual, musical) looks at itself exerting power and, therefore, creates for itself possibilities to repeatedly thwart its own power, inflating it only to deflate it better. (190)

"Displacement" is one word for the process of re-creating textual space, unsettling language by moving it from one space to another, or others. Displacement contains within it a notion of spatial contingency rather than fixity, a recognition that location is a matter of timing. Trinh suggests:

Displacing is a way of surviving. It is an impossible, truthful story of living in-between regimens of truth. The responsibility involved in this motley in-between living is a highly creative one: the displacer proceeds by unceasingly introducing difference into repetition. By questioning over and over again what is taken for granted as self-evident, by reminding oneself and the others of the unchangeability of change itself. (21)

Indeed, one of the ways in which power maintains itself is by insisting on its selfevidence. Power guarantees itself. The introduction of difference into this repetition requires, as Trinh points out, the maintenance of multiple positions in- 
between. These positions, by their very existence, question the authority of stable meanings which serve to flatten difference and disallow change.

The naming of a given tactical procedure as displacement implies not only the point of arrival of the displacement, but the point of departure-where it is displaced from-and the passage in-between. Thus displacement would seem to entail the recursive questioning of which Trinh speaks. And yet, for all its implied temporal contingency and fluidity, displacement can be strategic as well as tactical; the impossible story it tells may not be truthful, or its impossibility may be made manifest. To begin a textual confrontation: one might say that the film The World of Suzie Wong displaces questions of racial difference onto morality. The conflict between Robert and Suzie (thrice cited above) is defined in terms of his objection to her profession rather than in terms of her position as a woman of color, rather than as his own inability to deal with difference.

The film, however, does offer the possibility of reading differently, of seizing Morris's "propitious moments" where tactical intervention or appropriation may prove effective. I will not try to argue that reading this way is not a struggle; it is all too easy to read for similarity rather than difference. Morris makes the provisional nature of even attempting this way of reading clear: "unlike an exoticism which multiplies anecdotes of the same, a 'heterological' science will try to admit the alteration provoked by difference. Its reflexivity is not reinvested in a narcissistic economy of pleasure, but works to transform the conditions that make its practices possible, and the positioning of the other these entail" ("Banality" 34-35). Unfortunately, the "narcissistic economy of pleasure" is often all too attractive, and "anecdotes of the same" are far too easy to tell. Thus the importance of reading and interpreting lies in making the attempt to recognize moments of difference. This project entails an understanding of texts themselves as something other than "anecdotes of the same," even if those texts seem to do nothing but insist on their ideological self-similarity.

Two different ways of reading the beginning of The World of Suzie Wong illustrate the tactical mode of reading upon which I would insist. First, my interpretation: The film opens with Robert meeting Suzie on the Kowloon ferry, where he makes a sketch of her. She tells him she is Mee-ling Wong, the daughter of a rich man; she is a virgin and will "go to America next month to marry rich Chinese." Later, Robert meets a prostitute in the Nam Kok bar who looks very much like the girl from the ferry, his sketch of whom he has captioned, "Meeling-virgin." The girl denies that the picture is of her, saying that she has never met Robert before; she is a Wanchai bar girl, not the "stuck-up girl on ferry." Soon, though, she admits to having fooled him; it was indeed she on the ferryboat. "Why?" Robert asks. Suzie shrugs. "I like," she responds. She refuses to interpret her action for him; she defines it in terms of the pleasure it gave her, not the effect it may or may not have had on Robert's position and understanding. As a spectator and a theorist (not that the two can be separated), I like this moment. I read Suzie's response not only as a refusal to interpret, but also as an indication that she is possessed of agency and can choose when and how much of herself to reveal to this white man. 
Gina Marchetti offers a very different reading of this opening sequence in Romance and the "Yellow Peril": Race, Sex, and Discursive Strategies in Hollywood Fiction. She suggests:

Suzie Wong is...introduced as a confused soul in need of a more fixed identity....She first meets Robert riding on the Star Ferry, which connects the Kowloon Peninsula to Hong Kong Island. Her claims to be "rich" and a "virgin" seem suspect, belied by her body movements, speech, and overall behavior. Soon, Robert realizes that the Mei-ling [sic] he encountered on the ferry is simply a persona created by the troubled and exploited prostitute Suzie. Suzie, then, is first presented as a child-woman, playing games to escape her brutalized existence. (123)

Marchetti's reading of this sequence serves her interpretation of the film's overall ideological project; she argues that The World of Suzie Wong "promises the pleasure of imaginatively breaking conventions while maintaining the inevitability of the dominant culture's right to rule" (109). By not acknowledging-or, apparently, by simply being unable to see-that the film may be read in ways which destabilize the maintenance of dominant culture's supposedly inevitable dominance, Marchetti consequently does not see how the film both fights against and insists on its ideological project.

I recognize that the film will not let my propitiously chosen moment of Suzie's self-definition stand unchallenged. In a manner which bespeaks a closing off of the possibilities of Trinh's recursive questioning, the film returns to the issue of Suzie's masquerade, but this time tightens an ideological vise on its potential meanings and pleasures: Robert has taken Suzie out to dinner at a restaurant patronized mostly by whites, and he asks her, referring to her pretense, "Why did you make up all that nonsense?" This time, she answers with a more "complete" explanation, one that makes reference to a discursive world outside herself and her subjective pleasure: "Makes me feel good to pretend I'm somebody important." She does still interpret the action in terms of her own pleasure, but adds a nod to circumstances- "important" is a matter of being seen as important, having made Robert believe in Mee-ling Wong, virgin.

The fact that it is Robert who re-opens the issue points to the central, and most effective, strategy deployed by the film. Displacement, while it does entail the possibility of recognizing locational contingency, also implies the power to push from one discursive space to another. This example shows Robert as the one with the power to re-open issues, to push meanings around, to close off the openings that Suzie has left. Significant in this context is Trinh's discussion of

the way a tale is spun by many storytellers of Asian and African cultures. Nothing is explained, everything is evoked. When explanations were requested, the storyteller would 
pause, listen carefully, and after due consideration, repeat exactly the passage relevant to the question. No more, no less. Here, there is no necessity to reduce the plural meaning of the story to some flat explanatory answer, and the questioner is invited to listen again more mindfully to what he or she has missed. (162)

Within the film, Robert rarely listens more mindfully, rarely evinces attention to evocation, when he requests explanations. Indeed, the film illustrates his failure - and unwillingness - to accomplish this difficult sort of listening. This exchange follows Suzie's story of why she masqueraded on the ferryboat:

Suzie: But I not expect you to understand. You never have to do dirty job like me.

Robert: I suppose it's the usual stupid question, but...why do you?

Suzie: What else I do? Hong Kong full of hungry people. No one hire me. I never learn to read or write, even in Chinese.

Robert: You mean you can't read or write?

Suzie: Nobody ever teach me. When I was ten years old, old aunt take me to old uncle's to live. He say, "You do everything I ask." I very scared. I cry. But he not care. Then he throw me out. Not good for Chinese wife anymore. Not good for anything. What you think ignorant ten year old Chinese girl going to do?

Robert: I'm sorry I asked.

One way to read Robert's final line is as an expression of regret that cultural specificity has been allowed to enter the discussion, for he is stunned even by the possibility of illiteracy. For him to be more shocked at her illiteracy - and more willing to ask about it - than at the reasons for her prostitution (note that he does not exclaim "you mean your uncle raped you") indicates the terms under which he (and the film) may be said to accept her explanation. For Suzie, the illiteracy is incidental; it is the effect rather than the cause of the way she has been forced by circumstance to live. The rape is the defining event, for it meant that having lost her virginity, she could no longer be offered as a wife. Robert is sorry he asked precisely because she has offered the meaning on her terms and laid claim to a displacing power of her own. She asks the question now: "What you think ignorant Chinese girl going to do?" pushing him to return to his assumptions and question them, undermine them-and Robert has no reponse but regret.

The difference Trinh insists upon between "explanation" and "evocation" is at the heart of the distinction I want to make between the film and the 1957 novel from which it is adapted. The novel, written by Richard Mason, is a profoundly melodramatic tale that tells the story included in the movie, but also goes on to tell about Robert's success as an artist, Robert and Suzie's marriage, Suzie's incarceration for attempted murder, and, really the crowning touch, her bout with tuberculosis. In being very frank (for 1957) in its exhaustive detail 
concerning subjects like sex and disease, Mason and his novel yearn to be evocative, though cannot help functioning as an explanation. That is, Mason's book would like to evoke the world of Suzie Wong in all its resonance for its readership, but instead cannot help but explain that world, in Trinh's sense.

The language and structure of the book provide the justification for such a reading. Robert Lomax narrates the book in first person, and a primary part of this narration is his presentation of other characters' subjectivities: at one point Robert, in the process of painting Suzie, says, “...now there came into Suzie's eyes a twinkling half-mocking defiance, which might have been expressed in these words? 'All right, you may have conquered me-but only because I wanted to be conquered, and in a minute, when I've savored my destruction a bit longer, I shall become independent again"' (307). Robert is an artist, so if he is describing his painting of Suzie, there is at least a narrative reason for him to be offering this sort of narration of Suzie's thoughts. Lest such a reading explain the text and rescue it from condemnation, note that Robert here describes Suzie herself, not his canvas.

This episode raises the important question of Robert's place as an artist-interestingly, the novel articulates its own theory of art and the work of the artist. Robert says of his first attempts at painting: "I discovered the first, and possibly the only, truth about art: that its function was not to say, 'This is how $\mathrm{X}$ looked at a given moment,' but, 'This is how X looked to me'” (17). He calls for interpretation rather than representation, and additionally creates a divide between "art" and something else, implying that only art achieves this "how it looked to me" perspective, as opposed to all representation. Of course by saying that this is what art is, he validates not only his own work within the novel, but Richard Mason's work on/of the novel: surely the artist has every right to lay explanations over people, object, and events, all in the name of "how X looked to me." The artist/interpreter also gains the added cultural legitimacy afforded to that which attains the designation "art."

The film, too, has its own theory of art. Robert paints Suzie, and when he lets her see the portrait, she says, "I like it very much...but not look like me!" Robert replies, "It's what I think you look like-and that's the difference between an artist and a camera. An artist always tries to look deeper." The novel offers the artist as someone who sees things his way, thus implying that there is nothing essential about what he sees, whereas the film seems to want to say that the artist is supposed to capture some essential quality of the object he's trying to represent. But it is also significant that here artistry is contrasted to the work of the camera, which, if we're to believe Robert, deals in surface-which, paradoxically, is in fact universal, or at least, universally available.

The movie, in a sense, is right-surfaces do cause trouble, and Robertthe-artist, if he wants to maintain his position of power, has to get beneath them. The displacement of questions of difference onto questions of morality is cast in these terms; Robert gets beneath Suzie's "whore" surface to find her virginal heart. He gets under her skin, in a metaphorical sense. Further, her skin, in a nonmetaphorical sense-its color-is supposedly not important to him. He holds 
himself up as morally superior to the British residents of Hong Kong because while they are aware of skin color and seemingly nothng else, he is able, through a supreme act of racial tolerance, to think in other terms than the tone of Suzie's flesh.

So surface provides the ground on which Robert can secure his position, but interestingly enough, surface also allows the film its clearest openings for commencing the recursive questioning, and subsequent destabilizing, of meaning. The photography which comprises the film depicts the most troubling surfaces of all. The film offers location footage of Hong Kong, which on one level may reproduce Morris's exotic anecdotes of the same, but which also suggests that which lies beyond the Western movie camera's frame. Similarly, the stifling melodramatic narrative which ultimately uses that exoticism in the service of its ideological project cannot exhaust Hong Kong by defining the location as exotic.

More importantly, however, and most significantly, the film offers the face and body of Nancy Kwan. Through Nancy Kwan, Suzie Wong is embodied in a way that she cannot be in the novel, and that embodiment exceeds the film's ability to explain it (away). It is no accident that the contemporary reviews of the film point to Nancy Kwan, and to the photographic presentation of Hong Kong, as worthy of attention. Reviewers decry the film's narrative as melodramatic claptrap, but reserve praise for both the location photography and Nancy's charms. Bosley Crowther of the New York Times writes, "a new girl named Nancy Kwan plays [Suzie Wong] so blithely and innocently that even the ladies should love her. She and the scenery are the best things in the film" (3222).

Nancy Kwan's movie debut in The World of Suzie Wong inspires a flurry of extrafilmic discourse, the character of which bespeaks a certain discursive nervousness over how to define and contain her. Much is made of the fact that she is Chinese English by birth, and that despite her Asian heritage, she would be able to play a variety of ethnic and non-ethnic roles. Authors find her difficult to pin down: "Nancy's two-world background requires adjustment on the part of an interviewer who is trying to find out what goes on under the glossiness of her hair and behind her smoke-colored eyes" (Martin 40). How to place her tends to be at issue; does she belong in Hong Kong, China, England, Hollywood? No one is quite sure. Finally, however, the point is not whether or not her location can be fixed. Rather, her importance lies in the difficulty she embodies, the confusion she occasions. She cannot be fully narrativized, and thus cannot be fully contained. Richard Mason's novel explains the world of Suzie Wong. Nancy Kwan suggests the potential for evocation.

The trouble the film has in containing this kind of representation, representation that is put into play simply by the inclusion of Nancy Kwan as a figure in the text, brings me back to the question of radical criticism initially posed by Meaghan Morris. If I were to decry this film for its ultimately sexist and racist way of representing, I would fall into the trap of needing to fix meanings, reading for good or bad and no in-between, with the point of my project being to bring about "good" change within a "bad" system. It seems to me that this kind 
of work calls for far more delicate analysis, especially for someone in a position like mine-that is, a white female intellectual. I am in no position to speak the "goodness" or "badness" of discourses that purport to narrate events of which I am not a part; I find myself, rather, in the odd position of wanting to understand evocations, but needing them explained to me. Trinh's words about the storyteller point to this problem when she talks about repeating the relevant passages again-her formulation seems to presuppose a certain shared circumstance between the storyteller and the story-listener, so that if the listener does indeed listen more mindfully, s/he will indeed be capable of understanding the applicability of the repeated portion of the story. But when the listener and storyteller do not share cultures, the storyteller, depending on her purpose in telling the story, needs to walk a fine line between evocation and explanation.

My discussion of The World of Suzie Wong attempts to seize upon those moments which productively embody the tension between evocation and explanation in their recursive displacement of the solidity of ideology. Yet in no way do I mean to discount the ideological perniciousness of texts like The World of Suzie Wong in both its literary and filmic forms. These texts can do harm. But though they cannot make amends for the hurt they cause, they do offer the means of evoking a potential, tentative bridge between ignorance and understanding. The way to actualize that potential lies, I think, in the distinction between "strategy" and "tactics" taken from Morris. Strategy, once again, is concerned with the colonization of space, while tactics are about timing, seizing what is available in a given moment. Even when displacement is deployed in the service of an oppressive dominant, to read that displacement is to read a (temporal) process of movement from one location of meaning to another, which opens the door to multiplicity and change. To represent this process is to engage in the inbetween work of displacement-work that recognizes the distances between the locations it seeks to bridge, and that will take its time in getting there. Trinh says, "Inevitably, a work is always a form of tangible closure. But closures need not close off; they can be doors opening onto other closures and functioning as ongoing passages to elsewhere(-within-here)" (15). Even works which seem to be closures-such as the novel, The World of Suzie Wong - can function as such passages: by providing a door for, say, the certainly not unproblematically embodied portrayal of Suzie by Nancy Kwan.

The final moments of the film, too, provide space for such a passage. Robert proposes to Suzie:

Robert: Suzie...marry me. Go with me anywhere I go.

Suzie: Robert, I be with you until...until you say, "Suzie, go away."

Robert asks his question in spatial terms; marriage will be a matter of Suzie locating and relocating herself depending on his location. Suzie, however, does not answer on these terms-her response is temporal. Marriage is not just a matter of changing one's place, but arriving at places in time, an action which 
also implies process, or at least transition. Robert's final reliance on place as the defining element of marriage indicates that he is finally certain that he holds a place. Suzie, though, evinces no such assurance, and indeed, throughout the entire film she uses what is made available to her, always in contingent, provisional fashion. She casts her willingness to enter Robert's state of compromise in terms of the moment of its dissolution.

I will close by explaining the significance of the title of this essay. Early in both the novel and the film, Suzie suggests to Robert that she would like to be his "permanent girlfriend"- - that is, available for his pleasure alone-but only for as long as he will pay for her services. "Permanent" in this context refers not to a universal standard of temporal endurance, but to economic contingency. Sure, I'd like as much as anyone to find - and help to create-more, and more readily available, representations that really try to tackle this kind of uncertainty, that try to walk the line between assuming I can understand and explaining everything to death. But for the moment, for this moment, I'll ask Suzie to be my permanent girlfriend, and practice taking that walk with her.

\section{Works Cited}

Crowther, Bosley. Rev. of The World of Suzie Wong. New York Times 11 Nov. 1960: 36. Rpt. in The New York Times Film Reviews 1913-1968. Vol. 2. New York: The New York Times and Arno P, 1970. 3221-3222.

Marchetti, Gina. Romance and the "Yellow Peril": Race, Sex, and Discursive Strategies in Hollywood Fiction. Berkeley: U of Calif P, 1993.

Martin, Pete. "Backstage with Nancy Kwan.” Saturday Evening Post 10 Feb. 1962: 4045.

Mason, Richard. The World of Suzie Wong. New York: World Publishing Co., 1957.

Morris, Meaghan. "Banality in Cultural Studies.” Logics of Television: Essays in Cultural Criticism. Ed. Patricia Mellencamp. Bloomington: Indiana UP, 1990. 14-43.

Morris, Meaghan. “The Pirate's Fiancée: Feminists and Philosophers, or maybe tonight it'll happen." Feminism and Foucault: Reflections on Resistance. Eds. Irene Diamond and Lee Quinby. Boston: Northeastern UP, 1988. 21-42.

Morris, Meaghan. "Tooth and Claw: Tales of Survival and Crocodile Dundee." Universal Abandon?: The Politics of Postmodernism. Ed. Andrew Ross. Minneapolis: U of Minn P, 1988. 105-127.

Trinh T. Minh-ha. When the Moon Waxes Red: Representation, Gender, and Cultural Politics. New York: Routledge,1991. 